\title{
THE RELATIONSHIP OF CHILDRENS PREDICTED BEHAVIOUR TO THEIR OBSERVED BEHAVIOUR DURING DENTAL PROCEDURES
}

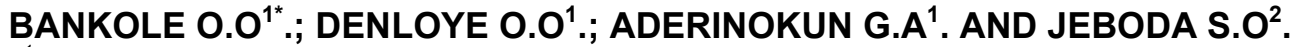 \\ ${ }^{1}$ Department of Preventive Dentistry, College of Medicine, University of Ibadan. Ibadan. \\ ${ }^{2}$ Department of Preventive Dentistry, College of Medicine, University of Lagos.
}

\begin{abstract}
The objective of this study was to assess the relationship of some Nigerian children's predicted behaviour to their observed behaviour during dental treatment. Two hundred and sixty children aged 2-15years, participated in this study. They were treated at the three government dental establishments in Ibadan, a city in southwestern Nigeria over a six-month period. The children's behaviour during the different phases of treatment were determined by the Frankl's Behaviour Rating Scale (Frankl et al, 1962). The findings revealed a direct relationship between the predicted behaviour and the actual manifested behaviour during dental appointments. During clinical examination $42.7 \%$ of presumed difficult children manifested positive behaviour in comparison to $95.1 \%$ whose mothers believed would be cooperative $(p<0.05)$. In the process of administering local anaesthesia, $21.9 \%$ of children who had been predicted to be uncooperative by their mothers complied, while $63.5 \%$ of those expected to be of good behaviour showed a positive response $(p<0.05)$. This study thus shows the importance of a mother being asked to make a prediction of the possible behaviour of her child before the dental treatment. This information will enable the dental practitioner take precautionary measures against untoward behaviour, which may be manifested. Appropriate behaviour management skills such as behaviour shapping, Tell-ShowDo, modeling and reinforcement instituted in children likely to behave poorly will enable each child come out with a positive impression at every attendance.
\end{abstract}

KEY WORDS: Dental anxiety, Fear, Dental Treatment, Child

${ }^{*}$ Author for Correspondence

\section{INTRODUCTION}

Results of research have revealed that fear of dentist persists in a substantial proportion of the population. A survey carried out among students in Bari area of Italy revealed that $38.7 \%$ of them were scared of the dentist (Desiate et al, 1997). Dionne et al,(1998) in a survey conducted in the United States of America reported that nearly $30 \%$ of the respondents claimed they were terrified about visiting the dentist. Furthermore, a comprehensive review of the literature on psychological research in dentistry indicated that at least $25 \%$ of adults are highly afraid of dentistry (Semenova et al, 1999).

Studies on problems of anxiety and behaviour associated with dental treatment in children have consistently revealed higher prevalence rates of negative attitudes and fear as compared to adults. According to Klingberg(1994), estimates of dentally fearful children vary and can be as high as $43 \%$ depending on the methods and populations. These fears not only disrupt the performance of clinical procedures but also tend to undermine the relationship between the dentist and their child patients (Brand, 1999). Weinstein et al, (1981) while assessing the practical experiences of private practitioners revealed that about $15 \%$ of practitioners reported $20 \%$ or more of their child patients as problematic, thus concluding that a serious recurring problem exists for many practitioners while treating children.

This phenomenon - fear, has been found to constitute one of the major obstacles to receiving dental treatment in many countries of the world (Naini et al ,1999). 
Literature has revealed that in certain circumstances doctors have been able to envisage anxiety in some patients and to some extent predict the probable outcome of their behaviour (Shafer, 1996). In a similar manner, mothers have been demonstrated to be capable of correctly predicting their children's behaviour to a large extent.

Martin et al, (1977) and Sote and Sote (1985) found an association between the mothers prediction of the child's behaviour in the dental clinic and the actual behaviour of the child. In a study of children from low socioeconomic families during their first dental visit, Hawley et al, (1974) found that children who were predicted to behave poorly tended to be more disruptive than others. These observations are perhaps borne out of the close mother - child relationship which should increase a better understanding and assessment of the child's likely behaviour.

In Nigeria, literature is very limited on this important aspect of dental care. In the only study conducted by Sote and Sote (1985) among Nigerian children, a relationship was found between the mother's prediction and the actual behaviour of a small group. There is a need to increase the level of knowledge in this field of dentistry. The objective of this study therefore was to examine the behaviour of children undergoing a greater variety and more complex treatment procedures. It is hoped that with this study information especially on their response in more stress-provoking situations will be established. This should facilitate better oral care delivery to Nigerian children.

\section{MATERIALS AND METHODS}

The study was conducted in Ibadan, a city located in southwestern Nigeria.

The subjects consisted of 260 children below the age of 16 years attending the three government dental clinics in the city. All the children seen and treated at these centers over a sixmonth period were included in the study. A team of dental surgeons and therapists who had earlier been informed according to a standard format carried out examination and treatment of the subjects. In addition to demographic information, the mother's prediction of her child's behaviour during the intended dental treatment was recorded in each case. An assessment of the behaviour of each child was made using Frankl's Behaviour Rating Scale (Frankl et al, 1962). The four-point scale of Frankl, which has been a prototype for many studies has been found reliable and is still being used till today.

The criteria for scoring are as follows:

Rating 1 - Definitely Negative- Refusal of treatment, crying forcefully, fearful or any overt evidence of extreme negativism.

Rating 2 - Negative-Reluctance to accept treatment. Some evidence of negative attitude but not pronounced.

Rating 3 - Positive - Acceptance of treatment, at times cautious, willingness to comply with the dentist, at times with reservation but patiently follows cooperatively.

Rating 4 - Definitely Positive - Good rapport with the dentist, interested in the dental procedures, laughing and enjoying the situation.

The Tell-Show-Do method (Addelston, 1959), was employed in communicating with the children in vocabulary suited to their ages. Demonstration of the exact procedure to be carried out was conducted. After ensuring proper completion of all forms, Frankl's ratings 1 and 2 were categorized as negative and ratings 3 and 4 as positive. The data were entered into an IBM compatible PC using the software EPI- INFO. Frequency tables of variables were generated and cross tabulations were used where necessary. Chi square test was employed to determine association between variables.

\section{RESULTS}

A total of 260 children aged 2-15 years drawn from the three study centers participated in the study. As revealed in Table 1, positive correlations were found to exist between children's predicted behaviour and the observed response to 
treatment at the pre-treatment stages. On entering the operatory $51(68.0 \%)$ of the children who had been predicted to be disruptive, reacted positively while $175(94.6 \%)$ predicted to comply, proved cooperative $(p<0.05)$. During examination $32(42.7 \%)$ presumed difficult children, manifested positive behaviour in comparison to $176(95.1 \%)$ whose mothers believed would behave well $(p<0.05)$.

During the treatment phase, a relationship between the predicted behaviour of the child and the actual behaviour manifested was established during prophylaxis, while administering local anaesthesia and during extraction (Table 2). Increased disruptive behaviour was manifested in children whose mothers believed would behave poorly. While having prophylaxis done only
$5(29.4 \%)$ of children whose mothers presumed will be difficult, complied, while $79(97.5 \%)$ of those predicted to be of good behaviour were positive $(p<0.05)$. During administration of local anaesthesia, $7(21.9 \%)$ of children who had been predicted to be uncooperative by their mothers were positive. A relatively higher percentage $40(63.5 \%)$ of the of those expected to be of good behaviour were cooperative $(p<0.05)$..

The extraction procedure revealed the same trend. Positive response was exhibited in $10(35.7 \%)$ of children predicted to be uncooperative while a greater proportion of the children expected to be of good behaviour $31(70.5 \%)$ were compliant $(p<0.05)$. Similar tendency was observed during restorative procedures. However, there was no statistical significance.

Table 1. The Relationship of Children's Predicted Behaviour to their Observed Behaviour at the pretreatment stage

\begin{tabular}{|c|c|c|c|c|c|c|c|c|c|}
\hline \multirow{3}{*}{$\begin{array}{l}\text { Mother's } \\
\text { Prediction of } \\
\text { Children's } \\
\text { Behaviour }\end{array}$} & \multirow{3}{*}{$\mathbf{n}$} & \multicolumn{2}{|c|}{$\begin{array}{l}\text { Enter } \\
\text { Operatory }\end{array}$} & \multicolumn{2}{|c|}{$\begin{array}{l}\text { Get } \quad \text { into } \\
\text { Dental Chair }\end{array}$} & \multicolumn{2}{|c|}{$\begin{array}{l}\text { Appearance } \\
\text { Operator }\end{array}$} & \multirow[t]{2}{*}{ the } & \multirow[t]{2}{*}{$\begin{array}{l}\text { Clinical } \\
\text { Examination }\end{array}$} \\
\hline & & \multicolumn{6}{|c|}{ OBSERVED BEHAVIOUR } & & \\
\hline & & -ve & $+\mathrm{ve}$ & -ve & $+\mathrm{ve}$ & $-v e$ & $+\mathrm{ve}$ & -ve & $+\mathrm{ve}$ \\
\hline Uncooperative & $\begin{array}{l}75 \\
(28.8) \\
\end{array}$ & $\begin{array}{l}24 \\
(32.0) \\
\end{array}$ & $\begin{array}{l}51 \\
(68.0) \\
\end{array}$ & $\begin{array}{l}28 \\
(37.3) \\
\end{array}$ & $\begin{array}{l}47 \\
(62.7) \\
\end{array}$ & $\begin{array}{l}28 \\
(37.3)\end{array}$ & $\begin{array}{l}47 \\
(62.7) \\
\end{array}$ & $\begin{array}{l}43 \\
(57.3) \\
\end{array}$ & $32(42.7)$ \\
\hline \multirow[t]{2}{*}{ Cooperative } & $\begin{array}{l}185 \\
(71.2)\end{array}$ & $\begin{array}{l}10 \\
(5.4)\end{array}$ & $\begin{array}{l}175 \\
(94.6)\end{array}$ & $\begin{array}{l}8 \\
(4.3)\end{array}$ & $\begin{array}{l}177 \\
(95.7)\end{array}$ & $3(1.6)$ & $\begin{array}{l}182 \\
(98.4)\end{array}$ & $9(4.9)$ & $176(95.1)$ \\
\hline & 260 & \multicolumn{2}{|c|}{$\begin{array}{c}X^{2}=33.21 \\
P<0.05\end{array}$} & \multicolumn{2}{|c|}{$\begin{array}{c}X^{2}=48.74 \\
P<0.05\end{array}$} & \multicolumn{2}{|c|}{$\begin{array}{c}X^{2}=64.81 \\
P<0.05\end{array}$} & \multicolumn{2}{|c|}{$X^{2}=91.82 ; P<0.05$} \\
\hline
\end{tabular}

$n=$ number of respondents; +ve = Positive; -ve = Negative; Figures in parenthesis are percentages (\%)

Table 2. The Relationship of Children's Predicted Behaviour to their Observed Behaviour during the treatment phases

\begin{tabular}{|c|c|c|c|c|c|c|c|c|c|c|}
\hline \multirow{3}{*}{$\begin{array}{l}\text { Mother's } \\
\text { Prediction of } \\
\text { Children's } \\
\text { Behaviour }\end{array}$} & \multicolumn{2}{|c|}{$\begin{array}{l}\text { Radiograph } \\
n=24\end{array}$} & \multicolumn{2}{|c|}{$\begin{array}{l}\text { Prophylaxis } \\
n=98\end{array}$} & \multicolumn{2}{|c|}{$\begin{array}{l}\text { Local } \\
\text { Anaesthesia } \\
\quad(n=95)\end{array}$} & \multicolumn{2}{|c|}{$\begin{array}{l}\text { Restorative } \\
\text { Procedure } \\
n=28\end{array}$} & \multicolumn{2}{|c|}{$\begin{array}{l}\text { Extraction } \\
n=72\end{array}$} \\
\hline & \multicolumn{10}{|c|}{ OBSERVED BEHAVIOUR } \\
\hline & -ve & $+\mathrm{ve}$ & -ve & $+\mathrm{ve}$ & -ve & $+\mathrm{ve}$ & -ve & $+\mathrm{ve}$ & $-v e$ & $+\mathrm{ve}$ \\
\hline Uncooperative & $\begin{array}{l}3 \\
(50) \\
\end{array}$ & $\begin{array}{l}3 \\
(50) \\
\end{array}$ & $\begin{array}{l}12 \\
(70.6)\end{array}$ & $\begin{array}{l}5 \\
(29.4)\end{array}$ & $\begin{array}{l}25 \\
(78.1)\end{array}$ & $\begin{array}{l}7 \\
(21.9) \\
\end{array}$ & $\begin{array}{l}2 \\
(33.3)\end{array}$ & $\begin{array}{l}4 \\
(66.7)\end{array}$ & $\begin{array}{l}18 \\
(64.3)\end{array}$ & $\begin{array}{l}10 \\
(35.7)\end{array}$ \\
\hline \multirow[t]{2}{*}{ Cooperative } & $\begin{array}{l}0 \\
(0)\end{array}$ & $\begin{array}{l}18 \\
(100)\end{array}$ & $\begin{array}{l}2 \\
(2.5)\end{array}$ & $\begin{array}{l}79 \\
(97.5)\end{array}$ & $\begin{array}{l}23 \\
(36.5)\end{array}$ & $\begin{array}{l}40 \\
(63.5)\end{array}$ & $\begin{array}{l}3 \\
(13.6)\end{array}$ & $\begin{array}{l}19 \\
(86.4)\end{array}$ & $\begin{array}{l}13 \\
(29.5)\end{array}$ & $\begin{array}{l}31 \\
(70.5)\end{array}$ \\
\hline & & & \multicolumn{2}{|c|}{$\begin{array}{c}\text { Yate's } \\
\text { corrected } \\
\mathrm{X}^{2}=49.41 \\
\mathrm{P}<0.05\end{array}$} & \multicolumn{2}{|c|}{$\begin{array}{c}\text { Yate's } \\
\text { corrected } \\
\mathrm{X}^{2}=14.78 \\
\mathrm{P}<0.05\end{array}$} & \multicolumn{2}{|c|}{$\begin{array}{c}\text { Yate's } \\
\text { corrected } \\
\left.X^{2}=0.30\right) \\
P>0.05\end{array}$} & \multicolumn{2}{|c|}{$\begin{array}{l}X^{2}=0.42 \\
P<0.05\end{array}$} \\
\hline
\end{tabular}

$n=$ number of respondents; +ve = Positive; -ve = Negative; Figures in parenthesis are percentages (\%) 


\section{DISCUSSION}

Many workers have found that, to a certain extent, mothers have been able to predict correctly the behaviour of their children in the dental clinic (Wright and Alpern 1971; Hawley et al, 1974; Martin et al, 1977 and Sote and Sote, 1985). The findings in this study have also shown that there is a direct association between the predicted behaviour of the child and actual manifested behaviour during dental appointments. It was observed that more negative behaviour was displayed in children whose mothers predicted would behave poorly. This association was noticed at the preliminary stages of treatment, during prophylaxis, administration of local anaesthesia and extraction. The same tendency was observed during restorative procedures

These findings are in congruency with those of Wright and Alpern (1971), Hawley et al, (1974) and Martin et al, (1977). Wright and Alpern (1971) however demonstrated that this result was valid in older children only. Even though these results are also consistent with those of Sote and Sote (1985), this study provides details on the relationship between the predicted and actual behaviour of the children under specific dental procedures as extractions, restorations and prophylaxis as opposed to merely treatments in general. The fact that the mothers prediction was accurate at virtually almost every stage of the treatment procedure has buttressed the validity of this finding. In other words the prediction of the mother has been shown to be invaluable in determining the expected behaviour of their children during dental appointments and should enable the dental practitioner to take precautionary measures in those envisaged to display untoward behaviour.

The main reason for unfavourable behaviour of children in the dental clinic is fear. Noise and vibration of the drill, the sight of the injection needle and sitting in the dental chair have been reported as particularly fear provoking (Willershausen et al, 1999). Most often than none, fear of pain appears to be the most important predictor of dental anxiety (Liddell and Locker 1997). Dental fear has been found to be a multifactorial problem encountered during dental treatment. The commencement of dental anxiety has been identified to be mainly in childhood (Locker et al, 1999). For this reason, it is pertinent that these fears are addressed early. If not they tend to persist into adulthood thus leading to an increase in frequency of missed or cancelled appointments and patients making only emergency dental visits (Smyth 1999, Skaret 2000).

The role of the dentist is important in developing an understanding or how children become dentally fearful. For this reason the dentist should identify the children with high dental anxiety status, help evaluate their fears and assist to build their strengths to overcome these fears. Conditioning appears to be largely responsible for the development of children's fears of dental treatment (Towend et al, 2000). As a result of this, the nature of past dental and medical experiences of children should be sought and where this has been unpleasant, steps should be taken to desensitize them from previous fears. Studies have also revealed that among other things, the behaviour of the dentist may play a part in the development of dental fear (ten Berge et al, 1999). Whilst friendliness is fundamental to behaviour management, the dentist will need to project a degree of firmness by being direct and authoritative when necessary.

A common theme throughout much of behavioural literature in paedodontics is that effective communication is important in development of good patient rapport and probably the basis for the success of many dentists with the children in their practices. The dental health team should recognize and utilize this.

Appropriate behaviour management skills such as behaviour shapping,

Tell-Show-Do, modelling and reinforcement should be instituted in children who are predicted to behave poorly by their mothers in order for each child to come out with a positive impression at every attendance. Dental 
visits should also be made as pleasurable as possible. A friendly atmosphere, welcoming smile of the receptionist and toys in the waiting area are invaluable in providing lovely lingering memories of the dental visit.

These measures would no doubt help to improve the acceptance of dental care in the child patients thus making them more receptive to oral health care. Since there are many other variables that may influence behaviour of children during dental appointment, it is important that further investigation is made into these other factors and their possible interrelationship.

\section{REFERENCES}

Addelston, H.K. (1959): Child patient training. Fortnightly Review of the Chicago Dental Society, 38: 7-9 and 27-29.

Brand, A.A. (1999): The child dental patient. Part I. The nature and prevalence of children's dental fears. South African Dental Journal, 54 (10): 482-7.

Desiate, A., Fanelli, M. and Milano, V. (1997): "Odontogenic anxiety. A study of a population of 1,500 students from the public schools in Bari area. Minerva Stomatologica, 46(4): $165-73$.

Dionne, R.A., Gordon, S.M., McCullagh, L.M. and Phero J.C. (1998): Assessing the need for anaesthesia and sedation in the general population. Journal of the American Dental Association, 129(2): $167-73$.

FrankI, S.N., Shiere, F.R. and Fogels, H.R. (1962): Should the parent remain with the child in the dental operatory? Journal of Dentistry for Children, 29: 150 - 163.

Hawley, B.P., McCorkle, A.D., Whitemann, J.K. and Ostenberg, P.V. (1974): The first dental visit for children from low socioeconomic families. Journal of Dentistry for Children, 41: 376- 38.

Klingberg, G., Berggrien, U. and Noven, J.G. (1994): Dental fear in an urban Swedish population: prevalence and concomitant factors. Community Dental Health, 11:208214.

Liddell, A. and Locker D. (1997): Gender and age differences in attitudes to dental pain and control. Community Dentistry and Oral Epidermiology, 25(4): $314-8$.
Locker D., Liddell,A.,Demster,L. and Shapiro,D.(1999). Age of Onset of Dental Anxiety. Journal of Dental Research 78(3): 790-6.

Martin, R.B., Shaw, M.A. and Taylor P. (1977): The influence of prior surgical experience on the child's behaviour at the initial dental visit. J.Dent Child, 44: 443-447.

Naini, F.B., Mellor, A.C. and Getz, T. (1999): Treatment of dental fears: pharmacology or psychology. Dental Update, 26(7):270-4,276.

Semenova, N.D., Kudriavaia, N.V. and Zhuruli, N.B. (1999): Psychological research in dentistry. Stomatologiia, 78(6): 57-64.

Shafer,A., Fish, M.P., Gregg, K.M, Seavello, J. and Kosek,P.(1996): Preoperative anxiety and fear: a comparison of assessments by patients and anaesthesia and surgery residents. Anaesthesia and Analgesia, 83(6): 1285-91.

Skaret, E., Raadal, M., Kvale, G. and Berg, E. (2000): Factors related to missed and cancelled dental appointment among adolescents in Norway. European Journal of Oral Sciences, 108(3): 175-83.

Smyth, J.S. (1999): A programme for treatment of severe dental fear. Report of three cases. Australian Dental Journal, 44(4): 275-8.

Sote, E.O. and Sote, G. A. (1985): An assessment of the cooperative behaviour pattern of children at the school of dentistry, Lagos University Teaching Hospital, IdiAraba. Nigerian Dental Journal, 6(1): 41-47.

Ten-Berge, M., Veerkamp,J. and Hoogstraten J.(1999) Dentists'behaviour in response to child dental fear. Journal of Dentistry for Children. 66(1): 36-40.

Townsend E., Dimigen G. and Fund D (2000): A clinical study of child dental anxiety. Behaviour Research and Therapy, 38(1) : 31-46.

Weinstein, P., Domoto, P.K and Getz T. (1981): Difficult children. The practical experience of 145 private practitioners. Paediatr. Dent., 3:303-305.

Willershausen, B., Azrak, A. and Wilms, S. (1999): Fear of dental treatments and its possible effect on oral health. European Journal of Medical Research, 4(2): 72-7

Wright, G.Z. and Alpern, G.D. (1971): Variables influencing children's cooperative behaviour at the first dental visit. Journal of Dentistry for Children, 38: 124-128. 